\title{
Paradigmas do campo comunicacional relacionados com a antropologia Giovandro Marcus Ferreira*
}

\begin{abstract}
RESUMO
Este artigo busca descrever alguns paradigmas do campo comunicacional, tendo como pano de fundo a relação criado com a antropologia em geral e a etnologia e a etnografia em particular. Este trabalho tem como ponto de partida três grandes eixos - a comunicação de massa, a comunicação interpessoal e a semiótica/análise do discurso, que servem para delinear a análise em busca de fronteiras e membranas com a abordagem antropológica. A partir do resgate dos paradigmas históricos que marcaram e marcam o campo comunicacional, o estudo faz uma descrição de migraçōes paradigmáticas relevando a porosidade em relaçāo ao estudo da cultura, onde os meios de comunicação se tornam cada vez mais mediadores culturais.
\end{abstract}

\footnotetext{
* Professor na Faculdade de Comunicação - UFBA, Doutor em Ciências da Informaçāo pela Universidade de Paris II (Panthéon-Assas)
} 


\section{Dos estudos antropológicos}

Nós partimos da seguinte premissa: Os estudos contemporâneos do campo comunicacional têm uma forte marca antropológica sejam eles visto através de paradigmas que tem como objeto a comunicação de massa, a comunicação interpessoal, ou então, o discurso mediático específico. Isso sem falar das ciências da informação, domínio pouco estudado nos cursos de comunicação social, pois se atém mais a substância, matéria prima (informação) e não ao processo. Este processo em questão é conduzido e é solidificado pela noção dos meios de comunicação como agente de mediação cultural.

Neste artigo que mostraremos mudança no campo comunicacional tendo como referência a contribuição da antropologia, podemos ver igualmente mudanças neste outro campo científico. A atividade antropológica foi esgarçada nos últimos tempos passando dos estudos das sociedades ditas primitivas, para as sociedades contemporâneas, com estudos sobre a vida urbana, a vida na empresa, entre outros. Além da migração do objeto, podemos também observar mudanças no tocante à metodologia e à problemática, indo de estudo de caso de âmbito micro às leis gerais da sociedade.

142 Normalmente, a "démarche" antropológica é vista em três momentos. ${ }^{1}$ Inicialmente, há o estágio da etnografia onde é feita a observação direta de uma unidade social, com o objetivo de classificala, descreve-la, analisar os fenômenos culturais particulares sejam eles ligados à crenças, instituições... Esta fase é caracterizada pelo estudo de campo (field work). As metodologias e técnicas empregadas na etnografia são bastante cogitadas numa série de abordagens de estudo da mídia, como mostra Thomas Tufte. ${ }^{2}$

A etnologia é um segundo passo e uma primeira busca de síntese, sem abandonar a observação direta. Segundo Lévi-Strauss, esta síntese pode ser efetuada em três direções: geográfica (integração de conhecimentos relativos a grupos vizinhos), histórico (reconstituição do passado de uma ou várias populações), sistemática (caso se isole tal conhecimento e busque um aprofundamento num determinado aspecto - costume, técnica, instituição etc). Nesta perspectiva a etnografia é uma etapa primeira da etnologia.

Por sua vez, a antropologia - dita cultural ou social corresponderá uma última etapa neste processo, tendo, por conseguinte, os dois outros momentos como preliminares. A antropologia visa, então, 
um conhecimento global do homem (desenvolvimento humano) abarcando suas dimensões geográfica e histórica. Tal conhecimento é válido para as sociedades ditas primitivas, como também as "civilizadas". fortemente marcadas pela vida urbana, pela presença da técnica. pela comunicação de massa.

A antropologia se afina ainda mais com o campo comunicacional quando o conceito de cultura é basicamente semiótico, onde o homem é visto como um animal emaranhado por teias de significado. O estudo da cultura passa então a ser reforçada enquanto análise destas teias, desdobrando numa ciência interpretativa. em busca de significado. e não tanto experimental a procura de leis. como fora enfatizada outrora. O fazer antropológica será uma busca de significados. almejando a "descrição densa" das estruturas de tais significados. Tal perspectiva abrange as diversas etapas esboçadas acima c a cultura. como sistemas entrelaçados de signos, passa a ser considerada, segundo Clifford Geertz, "não como um poder, algo ao qual podem ser atribuídos casualmente os acontecimentos sociais, os comportamentos, as instituições ou os processos; ela é um contexto, algo dentro do qual cles podem ser descritos de forma inteligível - isto é descrito com densidade".

Assim, na visão de Geertz. as várias etapals apresentadas são revisitadas e passam a ter características interpretativas. e tais interpretações mais amplas c abstratas. O estudo da cultura auxilial. portanto, na compreensão dos significantes que nos acedem a partir da circulação do discurso social, onde as diversas formas da sociedade. nada mais são do que substâncias da cultura - em destaque. tendo $\mathrm{cm}$ vista o objetivo do nosso artigo - as formas adquiridas na produção. no produto e na recepção mediática. ${ }^{4}$

\section{A comunicação de massa: do impacto à negociação}

A comunicação de massa surge como objeto de análise na esteira da sociologia do século XIX. como já mostramos num outro momento. ${ }^{5}$ O debate entre a noção de sociedade antiga $X$ moderna $c$ a caracterização da sociedade emergente. teve como desdobramento conceitual uma outra noção, que foi a sociedade de massa. A noção de sociedade desdobrou-se em outras noções de massivo: cultura de massa, comunicação de massa, homem-massa.

A sociologia continuou, ao longo do século XX. se ocupando dos meios de comunicação, que ficou conhecida como sociologia dos meios de comunicação. A problemática mobilizadora deste domínio de estudo, 
pode ser sintetizada da seguinte maneira: o que os meios de comunicação fazem com a sociedade, fazem com os indivíduos? Esta indagação mobilizou diversos modelos analíticos que, de maneira pedagógica, podemos dividir em dois grupos: (1) aquelas abordagens que reforçam o poder das novas tecnologias em geral e dos meios de comunicação em particular em relação à sociedade e aos indivíduos, (2) aquelas outras abordagens que dão ênfase ao equilíbrio entre os meios de comunicação, de um lado, e os indivíduos e a sociedade, de outro.

No primeiro grupo, as abordagens têm como ponto semelhante ênfase dada aos meios de comunicação na sua onipresença e onipotência na sociedade e em relação aos indivíduos. A força de tais meios é expressa nas suas ações de como fazer pensar, como não fazer pensar e o que pensar. Estes vários modelos, baseados numa sociedade de massa, evidenciam a venerabilidade e passividade dos indivíduos diante potência e ação dos meios de comunicação.

A teoria hipodérmica ou bullet theory já fala por si. Conhecendo a ação dos meios só resta constatar o estrago feito nos indivíduos e na sociedade. A sociedade vista sem tradições e instituições, os indivíduos atomizados e isolados, os meios de comunicação reinam, aparentemente, sem lei, eles sendo o rei da dinâmica social, na conquista de mentes e corações. A teoria crítica, também conhecida como Escola de Frankfurt, reforça esta perspectiva unilateral, tendo as características da indústria cultural como uma projeção na descrição dos indivíduos que estão em contato com ela. Há um salto analítico arbitrário nesta abordagem onde a caracterização da indústria cultural passa também a representar as características dos indivíduos que consomem os seus produtos culturais.

Os meios de comunicação continuam sendo o protagonista de outras abordagens, no caso duas hipóteses, que fazem coro a indagação gestada no interior da sociologia: o que eles fazem com as pessoas? Por um caminho idêntido (força dos meios e fragilidade dos indivíduos) chegam a conclusões aparentemente contraditórias. A hipótese do agendamento (agenda setting) destaca o que os meios de comunicação fazem pensar, levando a formação da agenda pública, pela os assuntos da ordem do dia e da hierarquia determinada entre eles por tais meios. A hipótese da espiral do silêncio vem, por sua vez, ressaltar o silêncio imposto pela opinião dominante, veiculada sobretudo pelos meios de comunicação, provocando assim uma imposição do silêncio naquelas supostas vozes discordantes, tornando a opinião majoritária ainda mais dominante.

Todas estas abordagens carregam no interior uma noção de sistema mediático, onde a presença e ação dos meios de comunicação 
se tornam robustas e determinantes acerca da dinâmica social. A sociedade e o indivíduo são fantasmas em tais abordagens, ou melhor. favas contadas, a partir do rei sol, os meios de comunicação.

A partir de um outro, mas numa démarche idêntica, podemos caracterizar o paradigma tecnológico. A expressão maior deste modelo foi McLhuan, influenciado pelas pesquisas de seu orientador Harold Innis. Eles partem de uma problemática que mobilizaram e mobilizam domínios científicos como a história, a sociologia: o que movimenta a história? Onde está o motor da história que provoca mudanças na sociedade, na maneira de pensar. de organizar suas instituições etc?

Estas questões mobilizaram Karl Marx, que buscou suas explicações na economia, nas suas modalidades de produção. O modo de produção é representativo do estágio em que se encontra uma determinada sociedade e a economia e as lutas em tomo dela suscitam. ao longo de um período, mudanças qualitativas. Max Weber. sem abandonar a economia, a relativiza colocando em cena a importância da religião. O viés explorado por Harold Innis e em seguida por McLuhan, será os modos de comunicação. como determinante da maneira de organizar conhecimento e de organizar a visão da realidade.

Os meios de comunicação para McLuhan têm um sentido amplo, que ultrapassa a noção que comumente é empregado. Uma rodovia é um meio de comunicação, a luz elétrica é um meio sem mensagem, mas não deixa de ser um meio na visão de Mcluhan. Para este teórico. o homem conhece mundo agindo sobre ele e para tal ação. ele cria extensões de seus sentidos, aumentando seu conhecimento no tempo e no espaço. Toda extensão afeta o "complexo psíquico c social", na palavra de McLuhan." A criação de novas tecnologias vai provocando gradativamente um ambiente humano totalmente novo. "O meio é a mensagem" pois será ele - meio ou tecnologia - que levará a uma mudança de escala, um novo modelo que introduz nos assuntos humanos. $^{7}$

Assim, retomando pesquisas do seu orientador. McLuhan afirma que "a palavra escrita criou o individualismo e o nacionalismo no século XVI", ou então, que "os efeitos da tecnologia não ocorrem no nível de opiniões ou conceitos, mas alteram os índices de sensibilidade ou modos de percepção rapidamente e sem qualquer resistência". ${ }^{8}$ Esta visão que coloca a tecnologia como agente de mudança social e individual, encontra desdobramentos em estudos mais recentes que podemos igualmente dividir em dois grupos, sem tentar ser categórico em tal divisão. De um lado, 
certos autores que evidenciam o avanço social e individual pela influência de novas tecnologias, uma visão apologética como Pierre Lévy ${ }^{9}$, e de uma certa maneira também a mediologia de Régis Debray ${ }^{10}$. De outro, uma visão marcada por um certo niilismo tecnológica, hoje expressa com bastante ênfase nos ensaios de Jean Baudrillard.

O paradigma da sociedade de massa e o paradigma tecnológico trabalham com um desequilíbrio entre a força dos meios de comunicação, das tecnologias (ativos) e a fragilidade, ou mesmo, a passividade da sociedade e dos indivíduos. Em geral, tais abordagens têm um caráter de ensaios, sem se ater, na maioria das vezes, em análises empíricas, em estudo de caso.

Esta visão, deste de cedo, está posicionada em contradição com uma outra abordagem que, por sua vez, limita a presença e o impacto dos meios de comunicação na sociedade. A teoria dos "efeitos limitados" ou "two step flow" é uma abordagem que coloca em relevo, desde a década de 40 , o contexto social como variável para se pensar o efeito dos meios de comunicação. Nesta investida, podemos situar um dos primeiros trabalhos de etnologia nos estudos dos meios de comunicação. A teoria dos "efeitos limitados" foi uma investida que se ocupou, sobretudo do estudo de grupos sociais, seu funcionamento, o papel de seus líderes. A 146 caracterização desses grupos servia para melhor compreender o tipo de filtragem ou de negociação com que era proposto, no caso, pelos meios de comunicação.

Este mesmo grupo investe, a partir dos anos 50, sob a iniciativa de E. Katz, no estudo da recepção deslocando a problemática para identificar a satisfação buscada pela audiência junto aos meios de comunicação, um desdobramento, visto por alguns, do paradigma funcionalista. ${ }^{11}$ Identificando a satisfação, estava igualmente revelando a necessidade do público ao consumir tal produto mediático. Mesmo que as metodologias e técnicas empregadas levaram à certas conclusões ingênuas, superficiais e às vezes igualmente falsas (o que levou ao recolhimento por algum tempo de tais pesquisas), a tendência em migrar a pesquisa da comunicação de massa junto ao público foi sendo ampliada.

Podemos aqui destacar duas vertentes que estão na ordem do dia e que resgatam alguns paradigmas comentados acima: os estudos culturais (cultural studies) e uma nova teoria da inovação tecnológica. Os estudos culturais surgem da clivagem dos estudos críticos (marcados por pensadores marxistas), pela semiologia francesa, mas submetendo suas hipóteses à verificação empírica. Havia, desde do início, uma 
preocupação de testar as hipóteses em campo, como demonstra já no subtítulo do clássico livro de Hoggard: The Uses of Literacy, aspectos da vida das classes populares. ${ }^{12}$ Além de ter esta característica empírica, a abordagem antropológica salta aos olhos, sobretudo no tocante à etnografia e à etnologia. ${ }^{13}$

O estudo da recepção se faz cada vez mais presente nos estudos dos meios de comunicação em geral, e em particular, como desdobramento de paradigmas que vertebraram a sociologia da comunicação de massa. O estudo da recepção enfatiza, normalmente, uma visão antropocêntica em vez de uma visão mediocêntrica dos meios de comunicação, ou então, como declara Martin Barbero, os estudos deixam os meios para passarem às mediações sociais. ${ }^{1+}$ E é nessa migração em direção à recepção que os estudos de comunicação se ancoram em conceitos como hegemonia, negociação, hibridização entre outros, para darem conta de tais mediações.

Um aspecto importante a destacar, nestes tempos de recepção em voga, através de uma "etnologia próxima". em contraste com uma "etnologia longínqua" da qual estamos habituados, é a introdução junto aos estudos de comunicação de problemas não resolvidos de campos que servem de alicerce para esta nova investida (semiologia e antropologia), como destaca Daniel Dayan, através de duas vertentes de problemas: ${ }^{15}$ (a) a primeira tange a produção do sentido do público. Quais são as bases conceituais, metodológicas. ideológicas em que foram assentadas as explorações do espaço misterioso que liga o texto ao leitor? (b) Já a segunda vertente está ligada à constituição dos próprios públicos. Os públicos existem fora da cabeça dos pesquisadores, dos seus escritos? Caso eles existam. tais públicos têm noção de suas existências? Que estatuto tem o público quando the é dado à palavra? ${ }^{16}$

O paradigma tecnológico, que sofreu várias críticas no passado. vem igualmente sendo revisitado por contribuições das ciências sociais em geral e da antropologia em particular. Nesta busca em constituir uma nova teoria das inovações técnicas, como almeja Patrick Flichy ${ }^{17}$. diversas disciplinas são solicitadas para tratar a técnica como um ensemble cultural e para ultrapassar distinções e dicotomias que fragmentaram e deturparam o estudo da técnica no passado: a separação entre invenção e difusão de uma inovação técnica, ou então, a separação entre a influência dos meios de comunicação na sociedade e as condições de emergência de novos sistemas de comunicação.

O reposicionamento da questão da técnica nas pesquisas de comunicação leva ao abandono da noção de causalidade (determinismo) 
em detrimento de uma análise das múltiplas mediações que ligam a técnica à sociedade, numa perspectiva circular. "Para explicar o aparecimento de um novo meio de comunicação, é preciso integrar a história na sua longa e curta duração, é igualmente conveniente articular a técnica e o social... O imaginário tem freqüentemente um papel essencial na elaboração de um novo meio de comunicação. Inicialmente o imaginário técnico: uma comunidade, de engenheiros e de inventores, se fixa coletivamente um desafio tecnológico... Mas as novas tecnologias são também detentoras de todo um imaginário social no qual participam os engenheiros, os inventores e uma parte do grande público."18

A problemática de uma teoria da inovação tecnológica se coloca sobre um plano de saber como se constrói as relações sociais na e pela tecnologia. Como se pode operar no interior de um mesmo círculo o quadro de funcionamento (produção), o quadro de utilização (recepção), contendo suas diversas etapas de formação, negociação, até chegar a um patamar de estabilidade de uma nova tecnologia e seu uso na sociedade.

Nesta ótica, o aparecimento de uma nova tecnologia será vista inicialmente, como sendo forjada pela cultura onde ela emerge. A tecnologia pode ser vista pelo imaginário e suas utopias, na interação dos diversos atores implicados no interior de um laboratório, seja igualmente no quadro de funcionamento, quer dizer, na fase de elaboração, através de sucessivas trocas: as negociações do quadro de funcionamento não ocorrem somente na fase de normalização, mas através de vários níveis, como os membros de uma equipe; entre suas comunidades técnicas sob forma de artigos, congressos; mas também entre os laboratórios e os fabricantes, entre estes e os responsáveis da produção em grande escala... até a negociação com os usuários. ${ }^{19}$

O quadro de utilização é um outro terreno fértil de inúmeras negociações. Um dos primeiros quadros de utilização é o quadro demonstrativo de uma invenção, aquele quadro que busca justificar o investimento para a criação de uma nova tecnologia (Graham Bell argumentava e demonstrava a necessidade da criação do telefone para ouvir música). Um segundo quadro de utilização será concebido pelos engenheiros de produção, que irão, normalmente, articular a nova invenção com objetos próximos, que já são utilizados. Em seguida, novos quadros de utilização irão aparecer na busca de atender as expectativas do público através de pesquisa-desenvolvimento, marketing... Depois 
dessas etapas, ainda existem outras no interior do grande público até que uma nova invenção se torne estável.

Todo este processo que se insere no quadro de utilização é pleno de estratégias e táticas que envolvem negociações de diferentes atores, não deixando espaços para se pensar a técnica de forma determinista ou causal. A questão da inovação tecnológica se torna assim objeto também de uma investida influenciada pela antropologia. levando à certos estudos, como de Bruno Latour acerca da produção de fatos científicos ${ }^{20}$, ou de forma mais pertinente, no tocante aos estudos da comunicação, como os trabalhos do CNET (coordenados por Patrick Flichy), pesquisando sobre as telecomunicações, em especial sobre a telefonia, através de una referência teórica um pouco mais complexa do que habitualmente a técnica é apresentada.2i

\section{Apelos à comunicação interpessoal e aos estudos dos discursos. \\ O estudo da comunicação interpessoal trouxe com frequiência} a problemática em tomo da trocá de informação. Como explicar certos ruídos ou distúrbios através do fluxo, como por exemplo. o fato que somente algumas ocorrências, no interior de uma multiplicidade delas. se tornam notícias? Quais são os possiveis critérios ou indicadores que poderão explicar esta defasagem? Como poderemos otimizar o fluxo informacional, transportando num menor tempo uma quantidade cadi vez maior de dados ou informação? ${ }^{22}$

Tradicionalmente, a comunicação interpessoal/grupal, no interior das pesquisas em comunicação, foi também marcada pela sociologia, em especial pela sociologia dos emissores. Uma dos primeiros modelos a afrontar com questões, que colocamos acima, foi a abordagem gatekeeper. Influenciada pela elaboração de Kurt Lewin, através de sua psicologia da forma (Gestalt), onde o conjunto é formado pelo sujeito e seu ambiente e que forma um "campo" estruturado e composto por zonas de atração e repulsão. Cada grupo tem o seu "campo" com seus canais de comunicação e suas barreiras. Toda nova informação é absorvida quando ela se integra ao "campo" do grupo.

A influência da psicologia de Kurt Lewin pode ser observada em relação à abordagem gatekeeper, como também na "two step flow" que apresentamos anteriormente. Como agente-filtro nesta última (two step flow), o líder adquire um papel fundamental assim como, num segundo momento deste tipo de pesquisa, a própria dinâmica do grupo. 
De uma maneira idêntica, a abordagem gatekeeper amplia igualmente a noção do selecionador, do porteiro que determina o produto informativo. Inicialmente, o gatekeeper era encarnado pela pessoa de algum(s) responsável(is) do órgão de imprensa, e em seguida, o gatekeeper passa pela noção de estrutura, que pode atingir vários níveis da estrutura do grupo ou da empresa. Nesta ampliação ou deslocamente da noção de gatekeeper, as distorções ou "ruídos" ao longo do fluxo comunicacional também passam a ter uma outra natureza. Elas deixam de ser ações voluntárias e passam a ser consideradas "distorções involuntárias". ${ }^{23}$

Paulatinamente, os estudos dos gatekeepers vão associando o trabalho de seleção com outros aspectos da produção da notícia: seleção e o conteúdo dos jornais e a imagem de realidade social de tais profissionais; a seleção, como fruto das práticas profissionais, e as rotinas estabelecidas na produção; a seleção e os valores partilhados e interiorizados pela comunidade dos profissionais. Neste novo patamar do estudo da produção da notícia, a seleção é um mote para ser feita uma etnografia das práticas sociais em torno da produção jornalística. Nesta fase, entramos num outro modelo de análise da produção jornalística, conhecido como newsmaking. ${ }^{24}$

Apesar da falta de seleção mais rigorosa dos materiais pesquisados e de planos de pesquisa pouco consistentes, o newsmaking tem o mérito de ir a campo, através de pesquisa empírica, com a técnica da pesquisa participante. Nesta investida tal abordagem prioriza dois eixos para explorar e explicar a produção jornalística: (1) a cultura profissional dos jornalistas e (2) a organização do trabalho - rotinas de produção. A noção de noticiabilidade (valores notícia) será então construída a partir dos valores imbuídos na cultura dos profissionais em questão e também da maneira como está estruturada a produção.

Este alargamento do estudo da comunicação em geral, e do jornalismo em particular, carrega em si uma riqueza acerca da perspectiva colocada no objeto analisado, como também na mudança de metodologias e técnicas utilizadas. Retomando Gaye Tuchman, Nelson Traquina, destaca a nova fase dos estudos da notícia através dos seus avanços, que sai do âmbito do indivíduo, passa ao nível da organização, e atinge ao nível da comunidade profissional. Este processo tende a ser ampliado ainda mais, quando observamos, em alguns estudos mais recentes, a articulação entre as ações da comunidade profissional e as implicações sociais e políticas, o papel social da notícia e a construção da democracia. ${ }^{25}$ 
Porém, dando destaque as contribuições da antropologia à compreensão do jornalismo, que representa nosso intuito deste artigo, podemos elencar 3 entre elas: (a) através da etnometodologia, a produção jornalística sai de uma visão mecânica e individual. A dimensão ultrapassa igualmente as fronteiras da organização, relevando a noção de cultura no interior da comunidade profissional; (b) a noção de rotina se torna balizadora para compreender a produção da notícia; (c) e por último, a partir desta nova base analítica e metodológica, a produção da notícia deixa na sua história a visão conspirativa em torno do jornalismo, sem perder, no entanto, a crílica acerca desta produção e dos valores que engendram a cultura jornalística. ${ }^{26}$

Partindo, igualmente, de uma problemática acerca do ruído e do fluxo comunicacional, tendo em vista a otimização de tal fluxo, a teoria informacional ou das telecomunicações, faz igualmente seu aparecimento no contexto de pesquisa da comunicação. A teoria informacional é essencialmente uma teoria da transmissão, segundo o esquema proposto por Shannon. Há uma fonte que emite sinais através de um aparelho de transmissão, que por sua vez, há um receptor que procede a conversão de tais sinais para um destinatário. A mensagem neste aparelho pode conter ruídos.

A teoria da informação se interessa ao código já que é ele torna possível a intelegibilidade transmissão da informação. O código é um conjunto de sinais, que serve de parâmetro para reduzir a eqüiprobabilidade na fonte. A informação é apreendida pelo seu lado mensurável no interior de um código, ou seja, o aspecto ressaltado é o sistema sintático. Neste caso, todo o aspecto do significado é desconsiderado, algo intrínseco a toda comunicação humana. Como diz Escarpit, "os teóricos da telecomunicação se interessam antes de tudo ao significante que deve ter um certo número de qualidades: resistência ao ruído, facilidade de codificação e decodificação, velocidade de transmissão. Eles se interessam ao significado na medida onde suas características têm uma incidência sobre o significante." ${ }^{27}$

Escarpit explora o exemplo do correio para ilustrar as preocupações da teoria da informação. O correio deve transmitir um telegrama, sem estar, no entanto, interessado na mensagem. Para o correio o significado da mensagem é indiferente na medida em que sua tarefa é a transmissão de uma quantidade de informação. Porém, tal modelo comunicativo teve e tem grande repercussão na sociedade e teve igualmente desdobramentos no interior da pesquisa em 
comunicação. $O$ lingüista russo Roman Jakobson foi um arauto na ampliação do modelo em questão, buscando articula.lo com a linguística. Para Jakobson, "a atividade comunicativa é representada como transmissão de um conteúdo semântico fixo entre dois pólos, igualmente definidos, encarregados de codificar ou decodificar o conteúdo, segundo as restrições de um código igualmente fixo." 28 Jakobson tem o mérito, mesmo se apropriando da teoria da informação, como destacamos na citação acima, de ser também um dos primeiros lingüistas a fazer a distinção entre o processo de produção e o processo de recepção de frases. Mesmo se esta distinção não tenha as características que nós empregamos atualmente. ${ }^{29}$

Recebendo influência de outras disciplinas, com destaque para a lingüística, a problemática da teoria da informação vai sendo ampliada e posicionada não somente junto ao significante, mas também à noção mais geral da significação. Este novo posicionamento será definido por alguns como o modelo semiótico-informacional. Ele guarda essencialmente o esquema precedente, porém o mais importante, é que a linearidade da transmissão se encontra arraigada ao funcionamento dos fatores semânticos, através do conceito de código. A comunicação torna-se a transformação de um sistema por um outro e não uma simples transmissão 152 de informação. ${ }^{30}$ Porém, a noção de código encontra-se ainda como balizador na relação dos sistemas em questão.

O código será a base contratual visto sobre dois aspectos: de um lado, sobre a articulação dos códigos, e de outro, sobre a situação específica do processo de comunicação. Este último está presente na articulação dos códigos e dos sub-códigos entre a produção e recepção da comunicação (desníveis de códigos, hipercodificação, hipocodificação...) e nas circunstâncias forjadas pelos fatores sóciais que provocam a assimetria nos dois pólos da comunicação. A noção de desajustamento na recepção da mensagem se torna cada vez mais evidente, assim como as implicações sócio-culturais.

Logo, apesar dos limites de tal modelo, ele tem a importância de abrir o processo comunicativo as interferências sociais. Isso possibilitará uma ampliação, em estudos posteriores, da influência de tais fatores sócio-culturais - na compreensão do processo comunicativo. Um novo modelo é esboçado para melhor apreender a relação entre produção e recepção, ou melhor, reconhecimento das mensagens. Uma característica importante neste novo momento é pensar tal relação, não mais restrita a noção de código, mas a partir de "conjuntos de práticas textuais", que leva 
em consideração da sincronia da comunicação, mas também de sua diacronia. Assim, poderemos pensar a problemática extrapolando a sincronia do processo de comunicáăa, levando igualmente em consideração a significação através do passado. A indagação pode ser deslocada da seguinte maneira: por que sem saber das notícias do dia seguinte, muitos de nós já temos cm mente qual jornal que gostaríamos de ler amanhã? Para entender o processo comunicação. e toda significação que cle comporta, somos levados cada vez mais à contextualização da comunicação em questão.

A noção de "conjunto de práticas textuais" encontra correspondência na antropologia de Cliffort Geertz. já citado anteriormente em nosso estudo. Para este autor, a cultura pode ser igualmente representada como conjuntos de textos e como um sistema de regras que determinam a criação e a orientação das novas produções textuais. Logo, os conjuntos de textos ou sistemas de signos que circulam numa cultura vão provocar influências sobre a produção e o reconhecimento de mensagens dos meios de comunicação. A competência interpretativa dos receptores está articulada com o consumo precedente de tais textos ou de tais sistemas de signos, em vez de uma apreensão de códigos de maneira pura e simples.

A produção e o reconhecimento de mensagens são edificados num diálogo intertextual, ou seja, a construção de um texto é "costurada" pelos ecos de outros textos precedentes. A perspectiva diacrônica do consumo de tais textos adquire relevância na produção e no reconhecimento de um processo comunicativo. Diante da complexidade, ou então, do mistério da recepção, no dizer de Daniel Dayan, a noção de recepção vem carregada de desníveis e de "efeitos possíveis". As implicações sócio-culturais tiram o receptor da condição de "depósito" da transmissão de mensagem e levam, por conseguinte. o estudo do signo e da análise do discurso para um conhecimento melhor da recepção, provavelmente articulando, nesta nova ctapa de construção de unna semiótica da recepção, uma aproximação entre o destinatário e o receptor, entre as abordagens sociológicas e semiológicas. Nas palavras de Mauro Wolf. poderemos estabelecer tal desafio na seguinte perspectiva: "conectar discursos. interações e contextos sociais, tal é o objetivo explicito de uma corrente para o qual o discurso não é somente um objeto semiótico, mas deve ser constantemente ligado a outros contextos caso se queira compreender sua dinâmica.".31

Para concluir esta nossa reflexão sobre a pesquisa de comunicação e a influência da antropologia, podemos terminar ilustrando com declaração 
de um teórico sobre sua atuação enquanto pesquisador no campo comunicacional. Inicialmente, ele começou suas pesquisas fazendo análises de filme, a partir das orientações de Christian Metz. Nas suas palavras, ele estava sentado na primeira fila de cadeiras do cinema. Em seguida, ele se preocupou com o estudo de recepção. Logo, ele foi sentar-se na última fila de cadeiras do cinema. Por fim, ele percebeu que para compreender o que se passava no cinema, ele tinha que sair da sala de cinema. Agora, afirma ele, que está fora da sala de cinema, na rua. Ele faz um percurso através de várias disciplinas, na troca de cadeiras, e das cadeiras à rua. Talvez nosso maior desafio, neste momento, é revisitar e analisar o acúmulo teórico que foi realizado nestes vários espaços (primeira, última fila e a rua) e a partir da contribuição entre eles, fazer avançar, um pouco mais, nossa compreensão do que se passar na produção, no produto e, sobretudo, nos mistérios ḋa recepção.

\section{Notas:}

${ }^{1}$ Ver LÉVI-STRAUSS, Claude, Anthropologie structurale, Paris, Plon, 1974. ${ }^{2}$ Ver TUFTE, Thomas, "Questões a serem estudadas em estudos etnográficos de mídia: mediação e hibridização cultural na vida cotidiana", in LOPES, Maria Imacollata Vassalo (org.), Temas 154 contemporâneos em comunicação, São Paulo, Edicon / Intercom, 1997. ${ }^{3}$ GEERTZ, C., A interpretação das culturas, Rio de Janeiro, Zahar Editores, 1978, p. 24.

${ }^{4}$ Idem ibidem.

${ }^{5}$ FERREIRA, Giovandro, "As origens recentes: os meios de comunicação pelo viés do paradigma da sociedade de massa", in HOHLFELD, A., MARTINO, L. e FRANÇA, V. (orgs.), Teorias da comunicação, Petrópolis, Editora Vozes, 2001.

${ }^{6}$ MCLUHAN, Marshall, Os meios de comunicação como extensões do homem, São Paulo, Cultrix, 1979.

${ }^{7}$ Idem Ibidem.

${ }^{8}$ MCLUHAN. M., Os meios são as massa-gens, $2^{\mathrm{a}}$. edição, Rio de Janeiro, Record, 1979, p: 21.

${ }^{9}$ LEVY, P., A inteligência coletiva, 2a edição, São Paulo, Edições Loyola, 1999. Ver, também, LEVY, P., Cibercultura, São Paulo, Editora 34, 1999.

${ }^{10}$ DEBRAY, Régis, Cours de médiologie générale, Paris, Gallimard, 1991.

${ }^{11}$ WOLF, Mauro, Teorias da comunicação, Lisboa, Presença Editorial, 1987.

${ }^{12}$ HOGGART, Richard, La culture du pauvre, Paris, Les editions de Minuit, 1970. 
13 "Estes estudos têm utilizado a abstração e a descrição formal para identificar elementos cruciais em um ensemble cultural vivido. As culturas são lidas " textualmente". Mas elas também têm sido vistas através de uma reconstrução de posição social dos usuários...A característica mais distinta é construída pelas conexões feitas entre ensembles culturais vividos e formas públicas. Tipicamente, os estudos têm se preocupado com a apropriação de elementos da cultura de massa e suas transformação de acordo com as necessidade e a lógica cultural dos grupos sociais. Os estudos sobre a contribuição das formas culturais de massa (música popular; moda, drogas, ou motocicletas) para os estilos sub-culturais, sobre a utilização das formas culturais populares pelas garotas e sobre a resistência dos garotos ao conhecimento e à autoridade da escola são exemplo disso." JOHNSON, Ricahrd, O que é, afinal , estudos culturais?, in, SILVA, Tomaz Tadeu da (org.), O que é, afinal, Estudos Culturais?, Belo Horizonte. Autêntica, 1999.

${ }^{14}$ MARTIN-BARBERO, Jesús, Dos meios às mediações, Rio de Janeiro, Editora UFRJ, 1997.

${ }^{15}$ DAYAN, Daniel, Les mystères de la réception, in revue Le Débat. No 71, Paris Gallimard, september-october 1992.

${ }^{16}$ Dayan se reapropriando da crítica de Hartley e em tom jocoso dispara: "As indústrias televisivas falam ao público. Os pesquisadores de diversas denominações falam do público ou em seu nome. Os estudos de recepção são aqueles que mais se aproximam de uma resposta do público. Eles deixam o público fala, mas um público que eles previamente o constituíram." Idem ibidem. p. 156.

${ }^{17}$ FLICHY, P., L innovation technique, Paris, Editions la Découverte, 1995.

${ }^{18}$ FLICHY, P., La question de la technique dans les recherches sur la communication, in BEAUD, Paul et alii., Sociologie de la communication, Paris Reseaux / CNET, 1997.

${ }^{19}$ Idem ibidem.

${ }^{20}$ LATOUR, B., A vida de laboratório, Rio de Janeiro, Relume Dumará, 1997, 21 Os trabalhos de Michel de Certeau têm muito contribuído para o reforço da articulação técnica e cultura. Ver CERTEAU, M. L'invention du quotidien I. arts de faire, Paris, Gallimard, 1990.

${ }^{22}$ Além destas questões, temos também aqueles que propõem uma antropologia da comunicação, ressaltando que na sociedade contemporânea a cultura é nada mais é do que comunicação. A comunicação (cultura) designa a troca de informação entre duas pessoas, como também a transmissão de mensagens pelos meios de 
comunicação. WINKIN, Yves, Vers une anthropologie de la communication?, in CABIN, Philippe, La communication - Etat des savoirs, Auxerre, Editions Sciences Humanes, 1998

${ }^{23}$ WOLF, Mauro, op. Cit.

24 "Uma característica da etnografia da comunicação, aplicada aos problemas do newsmaking é que permite a observação dos momentos e das fases de crise, quando se redefinem, de uma forma congruente, fenômenos e acontecimentos ambíguos, incertos e poucos claros, ou quando há reorganizações parciais do trabalho ou ajustamentos da linha editorial, que introduzem equilíbrios instáveis que devem ser estabilizados". Idem ibidem, p. 166.

${ }^{25}$ TRAQUINA, N. (org.), Jornalismo 2000 - o estudo das notícias no fim do século XX, in revista Comunicação e Linguagens - Jornalismo 2000, n² 27, Lisboa, Relógio D’Água, fevereiro de 2000.

${ }^{26}$ Idem ibidem.

${ }^{27}$ ESCARPIT, Robert, Línformation et la communication - théorie générale, Paris, Hachette, 1991, p. 30.

${ }^{28}$ JAKOBSON, R., Linguistique et théorie de la communication, in Essais de linguistique générale, vol. I, Paris, Les Editions de Minuit, 1963, p. 87.

$156{ }^{29}$ VERON, Eliseo, L'analyse du contrat de lecture: une nouvelle méthode pour les études de positionnement des supports de presse, in Les médias - expériences recherches actuelles applications, Paris, IREP, juillet, 1985.

${ }^{30}$ WOLF, M. op. cit.

${ }^{31}$ WOLF, Mauro, Recherche em communication et analyse du discours, in revue Hèrmes, $n^{\circ} 11-12$, Paris CNRS Editions, 1993, p. 217. 